\title{
FORMAÇÃO DOCENTE: CONTRIBUIÇÕES DA DIVERSIFICAÇÃO DOS INSTRUMENTOS AVALIATIVOS
}

\author{
TEACHER TRAINING: DIVERSIFICATION \\ OF EVALUATIVE INSTRUMENTS CONTRIBUTIONS
}

\section{FORMACIÓN DEL PROFESORADO: CONTRIBUCIONES DE LA DIVERSIFICACIÓN DE INSTRUMENTOS EVALUATIVOS}

Mari Clair Moro Nascimento

Raquel Lazzari Leite Barbosa ${ }^{\text {II }}$ Anelise Martinelli Borges de OliveirA III

Resumo Este estudo, com o objetivo de apresentar a diversidade de instrumentos avaliativos como um aspecto que pode favorecer a formação e a atuação de futuros professores, está embasado na abordagem qualitativa, sendo os dados coletados a partir de questionário. As informações adquiridas foram analisadas, categorizadas e quantificadas, tendo por fundamento a análise de conteúdo. O olhar se volta para a avaliação nos cursos de formação de professores, por acreditarmos que, se os futuros professores experienciarem a diversidade de instrumentos avaliativos, poderão ampliar seus conhecimentos a respeito do status da própria aprendizagem e da formação, valendo-se dessa prática quando estiverem no exercício da docência, tendo em vista favorecer a melhoria do conhecimento dos alunos com os quais estarão atuando no contexto da educação básica. A pesquisa foi realizada no ano de 2014, em uma turma do $2^{\circ}$. ano, em um curso de Pedagogia, cujo funcionamento ocorre em uma universidade pública situada no Estado do Paraná. Os dados possibilitaram perceber o portfólio e o mapa conceitual como os instrumentos avaliativos que mais proporcionaram aprendizagens, bem como a importância do feedback do professor aos alunos, por ser essencial a devolutiva acerca da qualidade das aprendizagens.

Palavras-chave: Instrumentos avaliativos; Avaliação formativa; Formação de profesSORES.

'Universidade Estadual Paulista (UNESP), Marília/SP - Brasil

"Universidade Estadual Paulista(UNESP), Assis/SP - Brasil

"IIUniversidade Estadual Paulista(UNESP), Marília/SP - Brasil 
Abstract This study, that aimed to present the diversity of evaluation instruments as an aspect which may contribute to the formation and performance of future teachers, is based in the qualitative approach and data collected from questionnaire. Information acquired were analyzed, categorized and quantified, on the grounds on content analysis. The observation turns to the evaluation in teacher training courses, because we believe that if student teachers experience the diversity of evaluation tools may expand their knowledge about the status of their own learning and training, making use of this practice when they are in the teaching profession in order to encourage the improvement of students knowledge who will be acting in the context of basic education. The survey was conducted in 2014, in a 2nd year classes in a Faculty of Education whose operation takes place in a public university located in the state of Paraná, Brazil. The data enable to realize the portfolio and the conceptual map as the evaluation instruments that provided more learning, as well as the importance of teacher's feedback to students, considering essential the return about the quality of learning.

Key-words: Evaluation tools; Formative assessment; Teacher training.

Resumen Este estudio, con el objetivo de presentar la diversidad de instrumentos evaluativos como un aspecto que puede favorecer la formación y la actuación de futuros profesores, se basa en el abordaje cualitativo, siendo los datos colectados a partir de cuestionario. Se analizaron las informaciones adquiridas, categorizadas y cuantificadas, teniendo por fundamento el análisis de contenido. La mirada se vuelve hacia la evaluación en los cursos de formación de profesores, por nuestra creencia que si los futuros profesores experimentan la diversidad de instrumentos evaluativos podrán ampliar sus conocimientos al respecto del status del propio aprendizaje y de la formación, valiéndose de esa práctica cuando estén en el ejercicio de la docencia, teniendo en vista favorecer la mejora del conocimiento de los alumnos con los cuales estarán actuando en el contexto de la educación básica. La investigación se realizó en el año de 2014, en una clase del $2^{\circ}$. año, en un curso de Pedagogía cuyo funcionamiento ocurre en una universidad pública ubicada en el Estado de Paraná. Los datos posibilitaron percibir el portafolio y el mapa conceptual como los instrumentos evaluativos que más favorecieron los aprendizajes, bien como la importancia del feedback del profesor a los alumnos, por ser esencial la devolutiva acerca da calidad de los aprendizajes. Palavras clave: Instrumentos evaluativos; Evaluación formativa; Formación de Profesores.

\section{INTRODUÇão}

Efetivar a avaliação das aprendizagens na perspectiva daquela que venha ajudar o aluno a aprender sempre mais e o professor a, sistematicamente, reformular suas práticas de ensino, demanda ao último, responsável pela organização do processo de ensinar e de aprender, conhecer e compreender os fundamentos e a prática da avaliação formativa, tendo em vista desenvolver junto aos educandos ações favorecedoras à ampliação dos conhecimentos. 
Considera-se como formativa "[...] toda a avaliação que ajuda o aluno a aprender a se desenvolver, ou melhor, que participa da regulação das aprendizagens e do desenvolvimento no sentido de um projeto educativo" (PERRENOUD, 1999, p. 101), pois nessa concepção avaliativa pressupõe-se a ação de intervir, levando em consideração as singularidades dos alunos. $\mathrm{O}$ ato de intervir para ampliar as aprendizagens tem ainda maior importância quando a avaliação acontece nos cursos de formação de futuros professores, espaço em que se considera essencial o estreitamento entre o pensar e o agir. De acordo com Zeichner (2003), há uma distância entre o dizer e o fazer, pois ainda que muito se fale sobre a necessidade de ter uma educação centrada no aluno, é bastante comum os estudantes das licenciaturas ficarem em anfiteatros, assistindo passivamente à instrução de como é preciso fazer, sem a vivência de tais práticas. Zeichner (2003, p. 40) diz que os professores formadores "[...] devem praticar o que pregam; do contrário, é provável que o currículo oculto da educação de professores, conflitante com a mensagem afirmada, venha a ser o fator mais influente na socialização dos educadores em formação".

Tal afirmação nos chama, portanto, a olhar para as práticas avaliativas empreendidas no interior das salas de aula dos cursos de licenciaturas, pois podem ser efetivadas tanto para "[...] melhorar as aprendizagens, ajudar os alunos a superar suas dificuldades [...]" (FERNANDES, 2009, p. 29), como para "[...] medir, preferencialmente, resultados de aprendizagem" (QUINQUER, 2003, p. 16), sendo que, na primeira proposta, a avaliação das aprendizagens acontece para ajudar os alunos a aprender sempre mais e, na última forma de avaliar, prevalece a atenção apenas para a quantidade de conhecimentos construídos pelos alunos, por indicar a aptidão ou não para prosseguirem à próxima etapa da escolaridade.

Para além de critérios que privilegiem exclusivamente a medição, a classificação e a seleção, a avaliação formativa visa orientar o aluno, "[...] procurando localizar as suas dificuldades para ajudar a descobrir os processos que lhe permitirão progredir na sua aprendizagem" (CARDINET, 1986, p. 14). Tal avaliação pode proporcionar ao aluno o reconhecimento de suas dificuldades, bem como as estratégias a serem utilizadas para a superação dessas.

Há que se atentar para uma visão organizada e sistematizada da atividade avaliativa, de modo que possa auxiliar, de fato, todos os alunos a aprender ao levar em conta suas reais necessidades, interesses, motivações e características próprias, devendo ser "[...] um processo social que põe em questão os sentidos da formação" (SOBRINHO, 2004, p. 703), porque, quando efetivamente planejada e executada, a avaliação: a) orienta os estudantes acerca do que precisam fazer para aprender; $b$ ) influencia acerca da motivação e percepção do que é importante aprender; c) estrutura a forma e o tempo que eles precisam dedicar ao estudo; d) amplia as aprendizagens; e) promove a autoavaliação e a autocrítica e f) desenvolve os processos de metacognição, autocontrole e a autorregulação (FERNANDES, 2006).

É importante que a prática avaliativa seja pensada como "[...] um juízo de valor, uma dada concepção de mundo e de educação [...]", sendo, portanto, intencional, por revelar “[...] quem é o educador quando interpreta os eventos da cena pedagógica" (SORDI, 2001, p. 173). Por isso, é necessário que a avaliação esteja presente desde o início do trabalho do- 
cente e não apenas em períodos isolados, como o término de cada semestre, por exemplo, já que "[...] é um meio e não um fim em si mesma" (CALDEIRA, 2000, p. 122).

Ainda que muitos aspectos do processo avaliativo possam ser objetos de reflexão, neste estudo priorizou-se a diversificação dos instrumentos avaliativos, pois no estudo de Nascimento (2012) fica em evidência que, entre outras, essa é uma das características apontadas por estudiosos do tema (ABRECHT, 1994; ALVARENGA; SOUZA, 2003; FERNANDES, 2004; 2006; 2008; 2009; GATTI, 2003; PERRENOUD, 1999) como essencial à efetivação da avaliação na concepção formativa, por possibilitar saber como está a evolução do aluno, a partir de informações coletadas em diferentes perspectivas. Diante do exposto, estabeleceu-se como objetivo deste estudo apresentar a diversidade de instrumentos avaliativos como um aspecto que pode favorecer a formação e a atuação de futuros professores. O objetivo foi estabelecido a partir da inquietação se e como os instrumentos avaliativos utilizados na disciplina de avaliação, ${ }^{1}$ ministrada em um curso de formação inicial de professores, favoreceram suas aprendizagens?

O estudo esteve embasado na pesquisa qualitativa, no intuito de dar atenção ao que fora anunciado pelos sujeitos participantes, pois " [...] esta metodologia observa, no mesmo movimento, o sujeito e a sociedade em interacção, mas também, e simultaneamente, os factos e as emoções que o acompanham" (GUERRA, 2008, p. 19). Os dados foram coletados no ano de 2014, em uma turma do $2^{\circ}$. ano, do curso de Pedagogia de uma universidade pública situada no Estado do Paraná, por meio de questionário aplicado a 29 alunos. A escolha pelo questionário se deu pelo fato de possibilitar a abrangência de um maior número de pessoas e, ainda, por garantir o anonimato dos sujeitos que podem expressar livremente o que pensam, a respeito do objeto de estudo (GIL, 1999). O questionário abrangeu quatro perguntas abertas: 1) Quais instrumentos avaliativos foram utilizados na disciplina de avaliação, para avaliar a sua aprendizagem? 2) Os instrumentos avaliativos the proporcionaram aprender? Por quê? 3) O que você aprendeu com os instrumentos avaliativos aplicados na disciplina de avaliação? e 4) Qual dos instrumentos avaliativos utilizados the proporcionou mais aprendizagens? Por quê? A interpretação dos dados se deu a partir da análise de conteúdos, por ser esse um método empregado para a análise de textos que visa produzir inferências, aspecto que "[...] muitas vezes implica em um tratamento estatístico das unidades de texto" (BAUER; GASKELL, 2002, p. 190-191).

O estudo revela que a diversificação dos instrumentos avaliativos, embasada nos fundamentos teóricos da avaliação formativa, pode favorecer o trabalho do professor formador, ao se ter conhecimento de como está o percurso acadêmico do aluno, bem como, ampliar as aprendizagens deste, favorecendo sua formação e sua futura atuação em sala de aula.

\section{AvaliaÇão da aPrendizagem: a ORGANizaÇão da disciplina EM um Curso de Pedagogia}

A referida disciplina, nesse curso específico de Pedagogia, é ministrada no $2^{\circ}$. ano, tendo em vista cumprir a carga horária de 72 horas, divididas em quatro horas semanais ao longo do $1^{\circ}$. semestre.

Não foi mencionado o nome da disciplina para garantir o anonimato da instituição.

152Comunicações | Piracicaba | v. 24 | n. 1 | p. 149-169 |janeiro-abril 2017 
Sua estruturação tem como objetivo possibilitar aos futuros professores a vivência do processo avaliativo na perspectiva formativa, no intuito de que essa experiência possa favorecer a sua efetivação, quando estiverem no exercício da docência, minimizando, ou quem sabe erradicando, a concretização da avaliação na concepção classificatória. Para isso, a disciplina foi organizada a partir de: 1) diagnósticos, no intuito de que o professor responsável por ministrá-la pudesse conhecer as concepções avaliativas dos alunos, bem como, acerca das aprendizagens que eles têm de cada assunto abordado; 2) leituras e reflexões sobre os textos indicados e 3) aplicação de uma diversidade de instrumentos avaliativos (UNIVERSIDADE ESTADUAL, 2014), na crença de que com essas experiências os futuros professores possam efetivar o processo avaliativo nos moldes daquele que visa ajudar o aluno a aprender e o professor a melhorar a sua prática de ensino, haja vista que, de acordo com Hadji (1994, p. 21), “[...] uma avaliação que não é seguida por uma modificação das práticas do professor tem poucas chances de ser formativa".

No programa da disciplina, foi possível encontrar: a ementa, os objetivos a serem atingidos, o conteúdo programático, os procedimentos de ensino e avaliativos e a bibliografia a ser utilizada. Na ementa consta que serão abordados os seguintes assuntos: 1) Fundamentos históricos, sociológicos e metodológicos; 2) Avaliação e seu papel no contexto atual do ensino; 3) Abordagens do ensino e da avaliação; 4) Técnicas e instrumentos de avaliação e 5) Feedback e seu papel no ensino (UNIVERSIDADE ESTADUAL, 2014).

No que se refere aos objetivos a serem atingidos estes são: 1) Compreender a relação entre ensino, aprendizagem e avaliação, reconhecendo a importância de vivenciá-la em sala de aula; 2) Conceituar avaliação da aprendizagem, identificando sua configuração nas perspectivas classificatória e formativa; 3 ) Entender as funções da avaliação da aprendizagem, relacionando-as ao trabalho pedagógico a ser implementado em sala de aula; 4) Diferenciar o processo de avaliação do instrumental que lhe fornece informações para a tomada de decisões; 5) Ter no instrumental avaliativo fonte informacional para a recomposição do processo de ensino e promoção de intervenções mediadoras e 6) Conhecer e analisar os diferentes instrumentos avaliativos compreendendo sua importância para a coleta de diferentes tipos de informações relativas ao conteúdo e forma da aprendizagem (UNIVERSIDADE ESTADUAL, 2014).

O conteúdo programático contempla uma diversidade de assuntos, divididos em subtópicos, conforme segue: 1) Ensino, aprendizagem e avaliação: a) Relações de interdependência; b) Implicação na prática pedagógica; 2) Avaliação da aprendizagem: a) Finalidades; b) Conceituação; c) Funções e modalidades: classificatória e formativa; 3) Regulação da aprendizagem: a) Conceituação; b) Tipos; c) Erro e suas funções; 4) Instrumental avaliativo: a) Etapas da construção; b) Importância dos critérios; c) Tipos: provas, mapas conceituais, portfólio, autoavaliação, observação, tarefa complexa, relatórios; 5) O conselho de classe e a avaliação da aprendizagem (UNIVERSIDADE ESTADUAL, 2014).

A respeito dos procedimentos de ensino, a indicação é de que esses precisam contemplar a interação professor / alunos e, também, alunos / alunos, tendo em vista favorecer reflexões acerca da inter-relação teoria / prática. Prevê, ainda, que os encontros aconteçam 
a partir de exposições orais e escritas. A respeito dos procedimentos avaliativos, indica a utilização de diversos instrumentos, no intuito de os futuros professores saberem o status da própria aprendizagem, bem como, do que precisam fazer para ampliar seus conhecimentos (UNIVERSIDADE ESTADUAL, 2014).

Na bibliografia, são apresentados diversos autores a serem estudados, sendo de leitura obrigatória (Quadro 1):

Quadro 1: Leitura obrigatória na disciplina de avaliação

\begin{tabular}{|l|l|}
\hline$N^{\circ}$. & \multicolumn{1}{|c|}{ Bibliografia } \\
\hline 01 & $\begin{array}{l}\text { ALVARENGA, G. M.; SOUZA, N. A. (orgs.). Avaliação possível e necessária. Londrina: Núcleo de } \\
\text { Estudos e Pesquisas Educacionais, 2003. }\end{array}$ \\
\hline 02 & $\begin{array}{l}\text { ÁLVAREZ MÉNDEZ, J. M. Aprender com os erros e aprender com as perguntas: sugestões para a } \\
\text { ação reflexiva e crítica. In: ÁLVAREZ MÉNDEZ, J. M. Avaliar para conhecer - examinar para } \\
\text { excluir. Porto Alegre: Artmed, 2002. }\end{array}$ \\
\hline 03 & $\begin{array}{l}\text { AQUINO, J. G. Erro e fracasso na escola - alternativas teóricas e práticas. São Paulo: Summus, } \\
1994 .\end{array}$ \\
\hline 04 & BALLESTER, M. (org.). Avaliação como apoio à aprendizagem. Porto Alegre: ArtMed, 2003. \\
\hline 05 & BARLOW, M. Avaliação escolar: mitos e realidades. Porto Alegre: ArtMed, 2006. \\
\hline 06 & SANMARTÍ, N. Avaliar para aprender. Porto Alegre: Artmed, 2009. \\
\hline
\end{tabular}

Fonte: Universidade Estadual, 2014.

A análise do programa da disciplina de avaliação nos possibilitou perceber que a maneira como foi estruturado pode ajudar o futuro professor a compreender a prática da avaliação formativa, isso claro, se o professor responsável pela disciplina atuar conforme indicam os fundamentos teóricos, pois, como diz Zeichner (2003), é preciso reduzir a distância entre o que se diz ser preciso fazer e o que realmente se faz.

\section{DiversifiCAÇÃo doS INSTRUMENTOS AVALIATIVOS NA CONCEPÇÃO DA AVALIAÇão FORMATIVA}

Concretizar a avaliação a partir da concepção formativa requer superar a prática que visa a "[...] predominantemente notificar, classificar, selecionar, excluir, consequentemente, punir" (SILVA, 2004, p. 59) o estudante, por uma prática que venha auxiliar o aluno a aprender, ação que precisa acontecer por meio da 1) intervenção do professor nas formas de ensinar; 2) de uma nova organização da sala de aula e 3) da participação ativa dos alunos (PERRENOUD, 1999) entre outras atitudes, pois a avaliação formativa "[...] se concretiza a partir da tomada de consciência do docente e do discente, no referente ao papel que cada um pode desempenhar, para que a evolução do conhecimento seja uma constante" (NASCIMENTO, 2012, p. 69). De acordo com Fernandes (2009), a avaliação na concepção 
formativa, nomeada por ele de formativa-alternativa, tem como objetivo principal melhorar as aprendizagens dos alunos, muito mais do que classificá-las, oportunizando-lhes a participação ativa no processo de aprender.

Nascimento (2012), ao apresentar seu estudo intitulado "Avaliação da aprendizagem: repercussões de modelos pedagógicos nas concepções docentes", aponta as características da avaliação na concepção formativa, a partir de pesquisa bibliográfica realizada em diversos estudiosos do tema (ABRECHT, 1994; ALVARENGA, SOUZA; 2003; FERNANDES, 2004; 2006; 2008; 2009; GATTI, 2003; PERRENOUD, 1999). Seu estudo revela, portanto, ações que caracterizam a avaliação na perspectiva formativa: 1) Mapear as aprendizagens em curso; 2) Regular o ensino; 3) Favorecer a autorregulação da aprendizagem; Pautar-se em critérios claros; 4) Diversificar os instrumentos avaliativos e 5) Promover feedback dialógico.

Entre as características apresentadas, destacamos, neste estudo, a diversificação dos instrumentos avaliativos, por possibilitar saber, a partir da utilização de um acervo variado de atividades, preparadas pelo professor, o que compreendeu ou não o aluno. De acordo com Silva (2004, p. 66), "[...] não se justifica o uso apenas de um instrumento avaliativo, pois quanto maior for o seu número, mais tipos de informações poderão ser coletadas, possibilitando uma melhor compreensão e intervenção sobre o objeto avaliativo". Diante do exposto, no intuito de saber como está a aprendizagem do aluno, a partir da utilização de diversas atividades, o professor poderá valer-se de:

[...] provas individuais, provas em grupo, provas com consulta, apresentações orais, exercício individuais e em grupo, relatos de experiência, contratos de tarefas, realização de experimentos e, especialmente, portfólios com amostra das realizações dos estudantes [entre outros] (ALVARENGA; SOUZA, 2003, p. 60).

Sobre a diversificação dos instrumentos avaliativos, encontramos no estudo de Nascimento (2012) que o professor precisa ter clareza a respeito da informação que deseja coletar, porque não se pode aplicar qualquer atividade, mas aquela que venha ajudar o professor a atingir o objetivo desejado, pois, de acordo com Gatti (2003), cada um deles oferece pistas diferentes a respeito do que o aluno aprendeu ou não. No entanto, ressaltamos que a diversificação dos instrumentos avaliativos perde seu valor quando não há o acompanhamento por parte do professor, pois cada um deles precisa ser analisado cuidadosamente,

[...] porque o importante é que, de posse dessas constatações, sejam desencadeadas ações de melhorias para os aspectos dificultadores. Diferente disso tende a prevalecer a simples verificação, a encerrar o ato avaliativo no momento em que se faz a identificação dos erros e dos acertos cometidos pelos alunos e seu subsequente registro sob a forma de escores (NASCIMENTO, 2012, p. 97).

Frente a esse apontamento, fica em evidência que a postura do professor é o que irá possibilitar a efetivação da avaliação das aprendizagens na perspectiva formativa, pois o importante é o que ele faz com os resultados coletados, a partir da diversificação dos instrumentos avaliativos. Então, não podemos dizer que o professor efetiva a avaliação formativa 
apenas porque diversificou os instrumentos avaliativos, sendo importante o uso que ele faz dos resultados obtidos. Ressaltamos que a diversificação dos instrumentos avaliativos, embasada na concepção da avaliação formativa, requer do professor interpretar, com o aluno, os resultados obtidos, porque se isso não acontecer não se concretiza a avaliação na concepção formativa, já que de posse dos resultados coletados, o professor precisa compreender as representações mentais dos alunos, ou seja, como estão pensando (JORBA; SANMARTÍ, 2003).

Frisamos, portanto, que a diversificação dos instrumentos avaliativos oportuniza ao professor maior clareza para agir, por possibilitar uma visão mais detalhada da realidade. Ainda, a análise detalhada dos instrumentos avaliativos utilizados viabiliza a efetivação dos processos de regulação e autorregulação, referindo-se o primeiro aos ajustes no processo de ensinar, estando assim relacionado às ações do professor e, o segundo, vinculado à atitude do aluno para organizar o próprio processo de conhecer. Desse modo, a avaliação está integrada ao processo de ensinar e de aprender, sendo protagonistas o professor e o aluno, porque a concepção formativa:

[...] pressupõe uma partilha de responsabilidades entre alunos e professores em matéria de avaliação e regulação das aprendizagens. Obviamente, os professores terão um papel que é, ou deve ser, preponderante em aspectos como a organização e a distribuição do processo de feedback, enquanto os alunos terão uma evidente preponderância no desenvolvimento dos processo que se referem à auto-avaliação e à auto-regulação de suas aprendizagens (FERNANDES, 2009, p. 60).

Nessa perspectiva, salientamos que a utilização da diversificação dos instrumentos avaliativos na sala de aula precisa vir acompanhada da análise pelo professor, por ser ele o profissional responsável por: 1) organizar o processo de ensino; 2) propor tarefas apropriadas aos alunos; 3 ) definir prévia e claramente os propósitos e a natureza do processo de ensinar e avaliar; 4) diferenciar as estratégias de ensino, conforme necessidade dos alunos; 5) atribuir feedback que apoie os alunos na regulação das suas aprendizagens e 6) criar uma comunicação interativa com os alunos (FERNANDES, 2009). Tais ações são ainda mais importantes quando nos voltamos para os cursos de formação de professores, visto que, conforme exposto por Tardif (2006), as concepções dos professores formadores servem de embasamento para as práticas dos futuros professores, quando estes estiverem na incerteza de como agir na sala de aula. Nesse contexto, efetivar a prática da avaliação, nas salas da universidade, como propõe a teoria da avaliação formativa, pode favorecer que os futuros profissionais, assim, concretizem o processo avaliativo, quando estiverem no exercício da docência. Por isso a importância de, após a aplicação de cada instrumento avaliativo, momento em que acontece a coleta das informações acerca do conhecimento do aluno, o professor fazer análises, tendo em vista tomar uma decisão, porque a avaliação, que visa ajudar o professor a ensinar e o aluno a aprender, demanda olhar para as estratégias de ensino e de aprendizagem que precisam de ajustes, pois é importante: 
[...] conhecer a qualidade dos processos e dos resultados. E, em educação, queremos conhecer para valorizar os processos que produzem certos resultados e intervir a tempo, se necessário, com a sincera intenção de assegurar o êxito dos que participam do mesmo processo educativo - decisão que brota da própria atividade avaliadora. Este deverá ser o sentido da avaliação formativa, que também será necessariamente contínua e pessoal (ÁLVAREZ MÉNDEZ, 2002, p. 64).

A cada instrumento avaliativo aplicado cabe ao professor reorganizar suas formas de ensinar, atendendo principalmente ao aluno que apresenta lacunas na compreensão do que está sendo estudado, concretizando assim a regulação do ensino. Ao mesmo tempo, o professor precisa intervir junto aos alunos de forma que estes possam concretizar a autoavaliação, a análise para o reconhecimento de como está a própria aprendizagem, no intuito de terem ações a favorecerem a melhoria do saber, concretizando-se assim a autorregulação, processo cujo objetivo é, após o aluno refletir sobre as próprias ações, buscar novos caminhos a serem trilhados para a ampliação da aprendizagem. Desse modo, avalia-se não somente para ajustar os processos de ensino, mas também para proporcionar ao estudante:

[...] reflectir sobre o processo de aprendizagem em si mesmo, sendo útil, principalmente para levar o aluno a considerar uma trajectória e não um estado (de conhecimentos), dando sentido à sua aprendizagem e alertando-o, ao mesmo tempo, para eventuais lacunas ou falhas de percurso, levando-o deste modo, a buscar - ou, nos casos de menor autonomia solicitar - os meios para vencer as dificuldades (ABRECHT 1994, p. 18-19).

Destacamos, portanto, a importância de que a prática da avaliação, nos cursos de formação de professores, aconteça embasada na teoria da avaliação na concepção formativa, por indicar como essencial a intervenção dos professores formadores, seja na reelaboração de novas estratégias de ensino ou com orientações aos alunos acerca da necessidade de buscarem outras estratégias para aprender.

Salientamos ainda, a partir do que evidencia Tardif (2006), sobre a formação da identidade docente, por afirmar que ela acontece ao longo da vida do professor, que não basta os futuros professores vivenciarem a prática da avaliação formativa apenas na disciplina de avaliação, sendo essencial que ela aconteça ao longo de todo o curso, porque o fato de experienciarem essa concepção avaliativa pode auxiliar na melhoria da aprendizagem, portanto, na formação e atuação docente, de modo que os futuros professores assim consolidem suas práticas, quando estiverem no exercício da docência.

\section{VIVÊNCIAS NA DISCIPLINA DE AVALIAÇÃo: O QUE DIZEM OS FUTUROS PROFESSORES}

A análise dos dados coletados aconteceu embasada nos fundamentos teóricos da análise de conteúdos, levando em consideração as indicações de Bauer e Gaskell (2002), quando estes anunciam que esse método acontece a partir de inferências do pesquisador, que 
se ampara no corpo teórico delimitado para gerar um tratamento estatístico das unidades encontradas no texto produzido pelos sujeitos pesquisados. Para isso, as respostas dos futuros professores foram analisadas, categorizadas e quantificadas, tendo em vista responder à inquietação se e como a diversificação dos instrumentos avaliativos na disciplina de avaliação, ministrada em um curso de formação inicial, favoreceram a aprendizagem.

Ao responderem à primeira pergunta "quais instrumentos avaliativos foram utilizados na disciplina de avaliação?", 100\% dos alunos apresentaram: prova formativa, portfólio, mapa conceitual, trabalhos individuais e coavaliação.

A informação fornecida pelos alunos possibilitou notar que a diversificação dos instrumentos avaliativos se fez presente na prática pedagógica desenvolvida em sala de aula, na disciplina de avaliação, aspecto que favoreceu ao professor identificar as compreensões e incompreensões dos alunos. De acordo com Nascimento (2012, p. 95),

\begin{abstract}
Adquirir os dados, a retratarem como está a evolução do aluno, a partir de um acervo variado, é fundamental ao professor, porque assim está embasado em diferentes perspectivas para a recomposição do ensino a ajudar na superação dos erros e aperfeiçoamento da aprendizagem.
\end{abstract}

Ou seja, de posse do status da aprendizagem do educando, compete ao professor reorganizar o ensino "[...] com intervenções corretoras, ancoradas em uma apreciação dos progressos e dos trabalhos dos alunos" (PERRENOUD, 1999, p. 78). Frente ao exposto, frisamos que o ato de avaliar não consiste em apenas contar erros e acertos dos alunos, mas em "[...] percebermos desvios e apontar saídas, caminhos, trilhas, não deixando acumular erros, descompreensões, mas chegando a tempo de fazer as correções processuais pertinentes" (SILVA, 2004, p. 66-67).

Nas respostas à segunda pergunta, "os instrumentos avaliativos lhe proporcionaram aprender? Por quê?”, 100\% dos futuros professores responderam que sim. Suas justificativas foram distribuídas em duas categorias, sendo que na primeira constam aqueles sujeitos que anunciaram os instrumentos avaliativos como reforçadores do conteúdo ministrado, $13,79 \%$, na segunda categoria aqueles que anunciaram que os instrumentos avaliativos ajudaram a aprender, $82,75 \%$. Um dos alunos (A1) não foi categorizado, porque não apresentou justificativa em sua resposta.

$\mathrm{Na}$ primeira categoria, foram incluídas as respostas dos sujeitos que apresentaram justificativas que se aproximam da avaliação da aprendizagem na concepção classificatória, na qual prevalece a importância da fixação/assimilação de conteúdos (A2; A7; A17) bem como, a indicação de como os alunos devem se comportar para adquirirem boas notas (A11), conforme indicam:

Os instrumentos avaliativos ajudaram a aprender porque reforçaram e fixaram o conteúdo que foi bem extenso (A2).

Esses instrumentos ajudaram a aprender porque moldam os alunos, indicando o que deve ser feito para ter boas notas (A11).

Os instrumentos avaliativos citados foram necessários para nossa formação 
porque com eles, conseguimos assimilar melhor os conteúdos (A17).

Vasconcellos (2000) diz que quando a diversificação de instrumentos avaliativos visa apenas à nota, como mostra A11, sua prática não está embasada nos fundamentos teóricos da avaliação formativa, a qual demanda ter ações que visem à melhoria dos resultados coletados, mas sim nos fundamentos da avaliação classificatória, já que se excluem do processo escolar os alunos que obtêm as notas consideradas baixas, por se entender que essas são a expressão da falta de inteligência do estudante. Nesta concepção,

[...] o principal propósito da avaliação é o de classificar, certificar, aceitando que há alunos que não podem aprender, desenvolvendo uma cultura cujos resultados estão em geral associados à desmoralização, à repetência e ao abandono escolar de milhares de crianças e jovens (FERNANDES, 2009, p. 29).

O importante, nesse contexto, é fixar / assimilar o conteúdo, conforme dizem A2 e A17, porque assim se garante a nota para "passar de ano", independente se o que foi trabalhado em sala de aula fora ou não compreendido.

Na segunda categoria, estão as respostas que se aproximam da avaliação concretizada na concepção formativa, como verificamos a seguir:

Pude verificar as falhas, corrigi-las e aprimorar meus conhecimentos e aprendizado (A3).

Os instrumentos que foram utilizados eram justamente o que estávamos aprendendo na matéria, e também tivemos sempre um acompanhamento da professora, que nos passava um feedback (A4).

Porque em cada um eu consegui aprender de um modo diferente. No mapa conceitual, pude organizar meus conhecimentos, na prova formativa, teve um retorno sobre meus erros, no portfólio pude fazer um resumo de toda a matéria trabalhada em sala de aula, e assim por diante. Assim, através dos diversos processos avaliativos consegui desenvolver a melhor maneira de aprender (metacognição) (A6).

Pois o objetivo foi sempre obter clareza sobre os conceitos trabalhados, e os instrumentos que foram utilizados durante as aulas favoreceram. As atividades em grupo também proporcionaram uma maior aprendizagem, pois discutimos, trocamos informações para obtermos conhecimento (A10).

Porque a cada limite que eu tive nos instrumentos avaliativos, a nova estratégia de aula me fazia superá-las (A20).

Notamos na fala dos futuros professores que várias foram as ações que lhes proporcionaram aprender, das quais destacamos: 1) a identificação das falhas e busca de estratégias para superá-las (A3; A9; A21; A23; A28; A29); 2) o feedback fornecido pelo professor responsável pela disciplina de avaliação (A4; A8; A14; A19; A22; A24); 3) as especificidades de cada instrumento avaliativo na avaliação das diferentes aprendizagens (A5; A6; A13; A15; A16; A25; A26; A27); 4) os trabalhos em grupo para a troca de informações (A10; A12) e 5) a utilização de novas estratégias de ensino pelo professor formador (A18; A20). 
Na terceira pergunta, a partir do questionamento "o que você aprendeu com os instrumentos avaliativos aplicados na disciplina de avaliação?”, as respostas foram distribuídas em três categorias. Na primeira, estão os sujeitos pesquisados que afirmaram ter compreendido 1) acerca da importância do feedback (A4; A6; A8; A9; A10; A24; A28), 24,13\%, na segunda categoria aqueles que indicaram aprender 2) a respeito da importância da diversificação dos instrumentos avaliativos (A5; A12; A13; A19; A20; A23; A25; A26), 27,58\%, e na terceira categoria os futuros professores que disseram ter entendido que os 3 ) instrumentos avaliativos possibilitam melhorias no ensino e na aprendizagem (A2; A7; A11; A14; A15; A16; A17; A18; A21; A22; A27; A29), 41,37\%. Dois dos sujeitos pesquisados não responderam à pergunta $(\mathrm{A} 1 ; \mathrm{A} 3) 6,89 \%$.

Sobre a importância do feedback, A4 e A6 dizem:

Aprendi a importância de utilizar diferentes tipos de instrumentos avaliativos, pois cada aluno aprende de um jeito diferente. É importante também, o professor passar um feedback ao aluno, para que esse possa saber se está no caminho certo ou não e como pode melhorar (A4).

Aprendi que existem diversas formas de avaliar um aluno e que a avaliação só será significativa se houver um retorno por parte do professor, se ele der um feedback ao aluno (A6).

A atribuição do feedback possibilita ao aluno tomar consciência de como está a própria aprendizagem, por ser o momento em que "[...] os professores comunicam aos alunos o seu estado em relação às aprendizagens e às orientações que, supostamente, os ajudarão a ultrapassar eventuais dificuldades" (FERNANDES, 2008, p. 353). Ao conceder feedback, o professor, além de posicionar o aluno acerca de como está o seu conhecimento, precisa indicar-lhe as ações a serem empreendidas para ultrapassar as dificuldades e ampliar as aprendizagens.

No que tange à diversificação dos instrumentos avaliativos, A13 e A25 relatam:

\begin{abstract}
Aprendi que cada instrumento tem sua especificidade e que todos são significativos desde que aplicado de maneira correta, visando melhorar o processo de ensino-aprendizagem (A13).

Aprendi a importância da concepção formativa e da diversificação dos instrumentos usados para saber como está a aprendizagem do aluno. No entanto, pude observar que poucos são os educadores que praticam a concepção formativa de forma eficiente (A25).
\end{abstract}

A respeito do que foi dito por A13, ressaltamos a importância de o professor ter clareza em relação ao que será coletado em cada instrumento avaliativo, tendo em vista escolher aquele que possibilitará saber como está a aprendizagem alvo, pois cada um deles possibilita compreender diferentes informações.

Acerca do mencionado por A25, fazemos uma ressalva a uma parte da sua fala, quando diz: “[...] pude observar que poucos são os educadores que praticam a concepção formativa de 
forma eficiente", por deixar em evidência que nem sempre a avaliação formativa é efetivada corretamente. Sua explanação nos leva a pensar que em algum momento das suas vivências escolares essa concepção foi apresentada, mas não foi efetivada conforme o proposto, porque a sua concretização demanda a transformação das práticas de ensino em pedagogias mais abertas, ativas e individualizadas, no intuito de abrir mais espaço à descoberta, à pesquisa $\mathrm{e}$ aos projetos, aspectos que possibilitam aos alunos ampliarem seus conhecimentos (PERRENOUD, 1999). No entanto, cabe destacarmos que a avaliação formativa demanda sim ações por parte do professor, por ser ele o responsável pelo ato de ensinar, mas não exclui o aluno das suas responsabilidades, porque the compete a busca por novas formas de aprender, caso aquelas utilizadas não estejam proporcionando avanços no conhecimento. Então, uma preocupação que se deve ter nos cursos de formação de professores é acerca do entendimento que esses futuros profissionais têm da avaliação na concepção formativa, aspecto que pode ser detectado a partir da diversificação dos instrumentos avaliativos, sendo, portanto, importante, a intencionalidade do professor formador em captar esse dado.

Acerca da anunciação de que os instrumentos avaliativos possibilitam melhorias no ensino e na aprendizagem, A15 e A21dizem:

\footnotetext{
Aprendi que com os instrumentos avaliativos é possível avaliar para buscar melhorar a aprendizagem. Que eles podem ser utilizados para desenvolver melhorar tanto a forma de ensinar quanto de aprender e ainda, desenvolvendo a formação dos alunos e também dos professores (A15).

Todos os instrumentos contribuíram de forma significativa para o meu aprendizado, cada um de sua forma, pois cada instrumento tem uma forma diferente de avaliar a aprendizagem do aluno, indicando o que ele precisa melhorar (A21).
}

As palavras de A15 indicam que a coleta das informações a partir da variedade de instrumentos avaliativos posiciona o professor a respeito de como está o seu ensino e o aluno acerca de como está a sua aprendizagem, tendo em vista que, se necessário, cada um deles tome a atitude que lhe cabe para a ampliação do conhecimento, ação que favorece a aprendizagem de ambos. Na fala de A21, fica claro que a diversificação dos instrumentos fornece diferentes informações, as quais requerem ações para a melhoria do que ainda se apresenta incompreendido.

$\mathrm{Na}$ quarta pergunta, "qual dos instrumentos avaliativos utilizados the proporcionou mais aprendizagens? Por quê?", as respostas foram divididas em cinco categorias: na primeira, o portfólio, (A1; A2; A3; A6; A7; A8; A9; A10; A12; A13; A14; A15; A16; A17; A18; A21; A22; A24; A26; A27; A28). 68,96\%, na segunda, o mapa conceitual (A4; A5; A11; A12; A19; A20; A23; A29), 27,58\%, na terceira, a coavaliação, (A4), 3,44\%, na quarta, a elaboração de prova, $3,44 \%$ e, na quinta, todos os instrumentos possibilitaram aprender (A25), 3,44\%. Nesta pergunta, as respostas superaram os 29 participantes, porque dois sujeitos (A4; A12) apresentaram dois instrumentos avaliativos.

A análise dos dados, fornecidos pelos futuros professores, possibilitou identificar o portfólio como o instrumento avaliativo que mais proporcionou aprendizagens, 68,96\%, conforme indicam: 
A partir do portfólio, pude mostrar o que aprendi, reavaliei os meus conceitos, refletindo se poderia melhorar e como faria para melhorar o conhecimento adquirido durante o semestre (A1).

Através do portfólio, foi possível ter uma releitura tanto dos conteúdos, como dos objetivos de cada aula, o que nem sempre é possível sem esse instrumento (A2).

Além de eu ter que buscar novos conhecimentos para superar meus erros, tive feedback da professora e pude retomar aquilo que não ficou claro para mim (A7).

O portfólio é uma avaliação mais individual. O professor conhece melhor o aluno e ajuda dando o feedback. É um instrumento que o aluno tem mais autonomia (A8).

Através da construção do portfólio, tive a oportunidade de revisar os conceitos aprendidos. Revendo aquilo que aprendemos e o que não aprendemos (A13).

Confesso ter conseguido realizar as atividades propostas sem ler inteiro os textos indicados, até a elaboração do portfólio, porque a partir do momento que precisei criá-lo, vi a enorme necessidade de ler os textos, foi onde aprendi mais a respeito dos conceitos e pude notar minhas maiores dúvidas (A14).

$\mathrm{Na}$ construção do portfólio, eu ia revendo o conteúdo aprendido em sala, ampliando ainda mais o meu aprendizado, e o que eu não sabia ou não havia entendido, pesquisava para tentar entender (A21).

De acordo com os alunos pesquisados, a realização do portfólio oportunizou: a) identificar o que fora ou não compreendido (A1; A7; A13; A14); b) buscar formas de ampliar os próprios conhecimentos (A1; A7; A8; A21); conhecer os conteúdos e objetivos a serem desenvolvidos em cada aula pelo professor (A2).

Segundo Hernandez (2000, p. 165),

A utilização do portfólio como recurso de avaliação baseia-se na natureza evolutiva do processo de aprendizagem. Oferece aos alunos e professores uma oportunidade de refletir sobre o progresso dos estudantes em sua compreensão da realidade, ao mesmo tempo em que possibilita introduzir mudanças durante o desenvolvimento do programa de ensino.

Em Villas Boas (2003), verifica-se que o portfólio é muito mais do que uma coleção de trabalhos realizados pelos alunos, sendo uma estratégia avaliativa que possibilita aos estudantes avaliarem o próprio progresso, estando eles, desse modo, na condição de sujeitos ativos no processo de aprender. Notamos, então, a partir do anunciado por Hernandez (2000) e Villas Boas (2003), que o portfólio possibilita a ambos, professor e aluno, voltarem os olhares para as próprias práticas, no intuito de estabelecerem mudanças, caso as estratégias utilizadas para ensinar ou aprender não estejam atendendo às necessidades dos estudantes, no sentido de ampliarem as aprendizagens.

Sobre a sua elaboração, Fernandes (2004) diz que não existe um modelo de portfólio, cabendo aos professores e alunos estabelecerem os objetivos a serem alcançados e a negociação de como será concretizado, de maneira a se constituir na amostra do que sabem e do 
que ainda precisam saber os aprendizes. No momento da sua organização, o aluno escolhe as atividades mais representativas do seu percurso de aprendizagem, ação que demanda olhar para todo o percurso. Desse modo, o aluno está envolvido no processo avaliativo, desempenhando uma ação mais participativa e reflexiva, sem minimizar a atuação do professor para o estabelecimento de ações a oportunizarem a ampliação do conhecimento dos estudantes. "Nestas condições, os alunos poderão, em princípio, ter mais oportunidades para mostrar o que sabem e são capazes de fazer e os professores mais oportunidades para conhecer as suas dificuldades e ajudá-los a superá-las" (FERNANDES, 2004, p. 21). Todavia, Fernandes (2004, p. 22) enfatiza que os portfólios por si só não garantem a avaliação na perspectiva daquela que objetiva ajudar o aluno a aprender, porque "[...] podem facilmente tornar-se meras pastas com colecções de trabalhos dos alunos. No entanto, se bem utilizados, podem influenciar positivamente as formas como se ensina, se aprende e se avalia". Sobre a sua utilização nos cursos de formação inicial para a docência, Fernandes e Simão (2007) apontam que é um instrumento essencial por possibilitar saber como está o desenvolvimento profissional do futuro professor.

Na segunda categoria, o mapa conceitual foi indicado por $27,58 \%$ como um dos instrumentos avaliativos favorecedores de aprendizagens.

A discussão feita na hora da produção do mapa conceitual possibilitou novos
conhecimentos, porque muitas vezes o conhecimento de um aluno complemen-
tava do outro (A5).
Eu não conhecia esse instrumento e o achei facilitador para os estudos. A partir
dele pude perceber conceitos que eu achava que já sabia, mas que na verdade
ainda apresentava dificuldades (A19).
Com o mapa conceitual eu consegui fazer as conexões e compreender definiti-
vamente os conteúdos (A20).
O mapa conceitual me auxiliou a construir uma melhor aprendizagem, apontan-
do minhas dificuldades e acertos diante do processo de avaliação (A29).

Os alunos pesquisados revelam em suas falas que o mapa conceitual possibilitou: a) interação entre os alunos, momento em que aprenderam com os conhecimentos dos outros colegas de sala (A5); b) identificação das próprias dificuldades e acertos (A19; A29 e c) melhor compreensão dos conteúdos (A20).

Mapas conceituais, segundo Moreira (1986, p. 18), são diagramas que indicam a relação entre os conceitos de uma disciplina ou área do conhecimento, podendo ser aplicados tanto para ensinar como para avaliar, pois "[...] podem ser utilizados para se ter uma imagem da organização conceitual - relações hierárquicas entre conceitos - que o aluno estabelece para um dado conteúdo", auxiliando o professor a reorganizar a sua prática pedagógica, tendo em vista a melhor compreensão pelo educando.

De acordo com Moreira (1986), não existem regras para a organização do mapa conceitual, sendo importante que ele evidencie a hierarquização dos conceitos pelos estudantes, já que "Essa forma de estruturação tem por alicerce a aprendizagem significativa, que consiste na integração de novos conceitos à estrutura cognitiva do aprendiz" (SOUZA; BORUCHOVITCH, 2010, p. 196). 
Como instrumento de avaliação da aprendizagem, mapas conceituais podem ser usados para se obter uma visualização da organização conceitual que o aprendiz atribui a um dado conhecimento. Trata-se basicamente de uma técnica não tradicional de avaliação que busca informações sobre os significados e relações significativas entre conceitos-chave da matéria de ensino segundo o ponto de vista do aluno. É mais apropriada para uma avaliação qualitativa, formativa, da aprendizagem (MOREIRA, 1997, p. 5).

Na terceira categoria, foi contemplada a coavaliação, anunciada por A4:

A coavaliação também foi bem interessante, pois me ajudou a ver a matéria através de outros olhos, me proporcionou complementar o que eu já tinha aprendido.

A coavaliação, também nomeada de avaliação por pares, concretiza-se no contato com o outro, sendo "[...] um momento em que os alunos podem se auxiliar mutuamente, observando o que cada um fez de inadequado e apontando uma possível solução" (SANTOS, 2011, p. 37). Ao vivenciarem a coavaliação, os alunos se encontram "[...] em situações de confronto, de troca, de interação, de decisão, que os forcem a explicar, a justificar, a argumentar, expor ideias, dar ou receber informações para tomar decisões, planear ou dividir o trabalho, obter recursos" (PERRENOUD, 1999, p. 99).

Na quarta categoria, a elaboração de prova, indicada por A27:

Ao elaborar a prova tivemos que pesquisar, quando pesquisamos para elaborar a prova, tivemos que tirar todas as nossas dúvidas para não elaborar questões confusas.

Foi possível notar, na fala de A27, que a sua preocupação se voltou para a pesquisa a respeito do assunto a ser abordado no instrumento avaliativo, tendo em vista a clareza nas questões a serem respondidas pelos assuntos, sem confundi-los, pois de acordo com Alvarez Méndez (2002, p. 117):

Se realmente pretendemos desenvolver a inteligência, é necessário fazer perguntas que a estimulem, e não que a paralisem ou a limitem a tarefas que não exigem reflexão, tarefas de repetição e de memória sem sentido, ou, o que é pior, a esclerosem.

E ainda, na quinta categoria, A25 diz ter aprendido com todos os instrumentos avaliativos:

Realmente não consigo apontar qual entre, tantos os instrumentos, foi eficiente para minha aprendizagem, pois todos me permitiram aprender de forma diferenciada (A25).

Acerca da informação de A25, recorremos às considerações de Despresbíteris (2011, p. 53), quando pontua que:

164Comunicações | Piracicaba | v. 24 | n. 1 | p. 149-169 |janeiro-abril 2017 
[...] a diversidade de instrumentos avaliativos precisa estar sistematizada, atender a uma metodologia própria da teoria e da prática da avaliação educacional e adequá-la à natureza do objeto avaliado, seja o ensino e aprendizagem, o currículo, o curso, o programa, a instituição. Diversificar não é simplesmente adotar vários instrumentos aleatoriamente, mas selecionar instrumentos que se complementem.

Frente ao exposto, percebemos que todos os instrumentos avaliativos empreendidos no processo avaliativo precisam auxiliar no processo de ensinar e de aprender. Para isso, é essencial que o professor tenha clareza dos dados que precisa coletar, sua intencionalidade, ou ainda, do que pretende desenvolver em seus alunos, lembrando sempre que fará toda a diferença a ação que será desencadeada após a identificação das informações coletadas, de modo que supere a verificação e se tomem as atitudes necessárias à ampliação das aprendizagens, sejam essas ações por parte do professor ou do aluno.

\section{CONSIDERAÇÕES FINAIS}

A concretização deste estudo nos permitiu responder à inquietação se e como os instrumentos avaliativos utilizados na disciplina de avaliação, ministrada em um curso de formação inicial de professores, favoreceram suas aprendizagens, atingindo o objetivo de apresentar a diversidade de instrumentos avaliativos como um aspecto que pode favorecer a formação e a atuação de futuros professores. A partir da coleta dos dados, entrelaçada com o corpus teórico delimitado, percebemos que a diversificação dos instrumentos avaliativos, empregada na disciplina de avaliação, no curso de Pedagogia pesquisado, favoreceu aos futuros professores aprendizagens que poderão fazer parte de suas práticas, quando estiverem no exercício da docência, pois, conforme anunciaram, proporcionou: 1) identificar as próprias falhas, tendo em vista a busca por estratégias que oportunizem a superação das mesmas; 2) reconhecer que cada instrumento avaliativo fornece um tipo de informação acerca das aprendizagens; 3 ) descobrir que os trabalhos em grupo propiciam a troca de informações e a ampliação dos conhecimentos; 4) constatar que o feedback é essencial no processo avaliativo e que 5) empreender o processo avaliativo a partir da diversificação dos instrumentos auxilia na melhoria do ensino e da aprendizagem, por fornecer informações a respeito de como está a atuação do professor e do aluno.

No entanto, quando A25 relata que essa ainda é uma prática de poucos professores, ressaltamos a importância e a necessidade dessa prática avaliativa acontecer nas demais disciplinas do curso, principalmente por se referir à formação inicial para a docência. Essa ressalva, de forma alguma tem por intenção afirmar que os demais professores do curso não efetivam suas práticas avaliativas embasadas nos fundamentos teóricos da concepção formativa, mas destacar a importância de serem concretizadas de maneira a ampliar os conhecimentos dos futuros professores de como podem agir para mapear as dificuldades dos alunos e, na sequência, ter atitudes que lhes ajudem a superá-las. Conforme também exposto, quando da análise da fala de A25, torna-se imprescindível o professor formador 
atentar para a maneira como os futuros professores compreendem a avaliação formativa, porque podem reconhecer práticas avaliativas como ineficientes, a partir de uma compreensão errônea da sua teoria.

Outro aspecto que cabe retomarmos diz respeito ao que fora inicialmente indicado por Zeichner (2003), ou seja, a necessidade de se reduzir a distância entre o dizer e o fazer nos cursos de licenciatura, porque não basta dizer aos futuros professores como se deve executar o processo avaliativo, porque eles precisam vivenciar tais práticas, visto que, segundo Tardif (2006), a identidade docente se dá a partir das vivências que os futuros professores tiveram ao longo da vida, podendo, por conseguinte, as práticas dos professores formadores interferir na atuação dos mesmos, quando estiverem no exercício da docência.

A pesquisa possibilitou saber também que a disciplina de avaliação foi efetivada conforme consta no programa, cumprindo assim o indicado por Zeichner (2003), no que se refere à necessidade de se reduzir a distância entre o dizer e o fazer, até porque seria uma contradição acontecer de outra forma, visto ser uma disciplina que visa ensinar o futuro professor a avaliar. Oportunizou ainda, identificar que, entre os instrumentos avaliativos efetivados na disciplina de avaliação, foram mais indicados, como aqueles que oportunizaram aprendizagens, o portfólio e o mapa conceitual. Outro aspecto que merece ser enfatizado é o fato de ter sido concedido feedback, do professor formador ao futuro professor, no desenvolvimento da disciplina, porque a diversificação dos instrumentos avaliativos precisa contar com a atuação do professor, pois por si só não garante a ampliação das aprendizagens.

\section{REFERÊNCIAS}

ABRECHT, Roland. A avaliação formativa. Portugal: Edições ASA, 1994.

ALVARENGA, Georfrávia Montoza; SOUZA, Nadia Aparecida de. Avaliação: possível e necessária. Londrina: Núcleo de Estudos e Pesquisa em Avaliação Educacional, 2003.

ÁLVAREZ MÉNDEZ, J. M. Avaliar para conhecer - examinar para excluir. Porto Alegre: ArtMed, 2002.

AQUINO, J. G. Erro e fracasso na escola - alternativas teóricas e práticas. São Paulo: Summus, 1994.

BALLESTER, M. (org.). Avaliação como apoio à aprendizagem. Porto Alegre: ArtMed, 2003.

BARLOW, M. Avaliação escolar: mitos e realidades. Porto Alegre: ArtMed, 2006.

BAUER, Martin W.; GASKELL, George. Pesquisa qualitativa com texto, imagem e som: um manual prático. Petrópolis: Vozes, 2002.

CALDEIRA, Ana Salgueiro. Ressignificando a avaliação escolar. In: . Comissão

Permanente de Avaliação Institucional: UFMG-PAIUB. Belo Horizonte: PROGRAD/ UFMG, 2000, p. 122-129. 
CARDINET, Jean. Linhas de desenvolvimento dos trabalhos actuais sobre a avaliação formativa. In: ALLAL, Linda, CARDINET, Jean; PERRENOUD, Philippe (Orgs.). A Avaliação Formativa num Ensino Diferenciado. Coimbra: Livraria Almedina, 1986, p. 289-306.

DEPRESBÍTERIS, Léa. Avaliação da aprendizagem: casos comentados. Pinhais: Melo, 2011.

FERNANDES, Domingos. Avaliação das aprendizagens: uma agenda, muitos desafios. 2004. Disponível em: http://repositorio.ul.pt/bitstream/10451/5509/1/ Avaliac\%CC\%A7a\%CC\%83o\%20das\%20aprendizagens-Uma\%20agenda, \%20muitos\%20desafios.pdf. Acesso em: $1^{\circ}$. jun. 2015.

. Avaliação, aprendizagens e currículo: para uma articulação entre investigação, formação e práticas. In: BARBOSA, Raquel Lazzari Leite (org.). Formação de educadores: Artes e técnicas - Ciências e políticas. São Paulo: Editora UNESP. 2006.

. Para uma teoria da avaliação no domínio das aprendizagens. Estudos em Avaliação Educacional. São Paulo, v. 19, n. 1, p. 347- 372, set./dez. 2008.

. Avaliar para aprender: fundamentos práticas e políticas. São Paulo: Editora UNESP, 2009.

FERNANDES, Maria da Conceição Neves; SIMÃO, Ana Margarida Veiga. 2007. O portfolio na educação de infância: estratégia de reflexão dos educadores e das crianças. In: SIMÃO, Ana Maria Veiga; SILVA, Adelina Lopes da; SÁ, Isabel (orgs.). Auto-regulação da aprendizagem. Das concepções às práticas. Colecção Ciência da Educação. Lisboa: EDUCA, 2007, p. 195-224.

GATTI, Bernadete. O professor e a avaliação em sala de aula. Estudos em Avaliação Educacional. São Paulo, n. 27, jan./jun. 2003. Disponível em:Acesso em: 21 jul. 2011.

GIL, Antônio Carlos. Como elaborar projetos de pesquisa. Atlas: São Paulo, 2007.

GUERRA, Isabel Carvalho. Pesquisa qualitativa e análise de conteúdo - Sentidos e formas de uso. São Paulo: Princípia Editora, 2008.

HADJI, Charles. A avaliação, regras do jogo: das intenções aos instrumentos. Portugal: Porto Editora, 1994.

HERNANDEZ, Fernando. Cultura Visual, mudança educativa e projeto de trabalho. Tradução Jussara H. Rodrigues. Porto Alegre: Artmed, 2000.

JORBA Jaume; SANMARTÍ, Neus. A função pedagógica da avaliação. 2003. In: BALLESTER, Margarita. Avaliação como apoio à aprendizagem et al. Porto Alegre: Artmed, 2003, p. 23-45.

MOREIRA, Marco Antônio. Mapas conceituais.Caderno Catarinense de Ensino de Física. Florianópolis, n. 3, v. 1, p. 15-25, abr. 1986. Disponível em: file://E:/Downloads/793423885-1-PB.pdf. Acesso em: $1^{\circ}$. jun. 2015. 
. Mapas conceituais e aprendizagem significativa. 1997. Disponível em: http:// www.if.ufrgs.br/ moreira/mapasport.pdf. Acesso em: 5 set. 2015.

NASCIMENTO, Mari Clair Moro. Avaliação da aprendizagem: repercussões de modelos pedagógicos nas concepções docentes. 2012, 125s. Dissertação (Mestrado em Educação) Universidade Estadual de Londrina. Londrina, 2012.

PERRENOUD, Philippe. Avaliação: da excelência à regulação das aprendizagens. Porto Alegre: Artes Médicas, 1999.

QUINQUER, Dolors. Modelos e enfoques sobre avaliação: o modelo comunicativo. In: BALLESTER, Margarita. Avaliação como apoio à aprendizagem. Porto Alegre: Artmed, 2003, p. 15-22.

SANMARTÍ, Neus. Avaliar para aprender. Porto Alegre: Artmed, 2009.

SANTOS, Edirnelis Moraes dos. A coavaliação como instrumento formativo no ensino-aprendizagem da produção escrita em português como língua estrangeira. Ciência \& Cognição. Rio de Janeiro, v. 16, n. 3, p. 37-42, 2011.

SILVA, Janssen, Felipe da. Avaliação na perspectiva formativa-reguladora: pressupostos teóricos e práticos. Porto Alegre: Mediação, 2004.

SOBRINHO, José Dias. Avaliação ética e política em função da educação como direito público ou como mercadoria? Educação e Sociedade. Campinas, v. 25, n. 88, p. 703-725, out. 2004.

SORDI, Mara Regina de. Alternativas propositivas no campo da avaliação: por que não? In: CASTANHO, Sérgio; CASTANHO, Maria Eugênia (orgs.). Temas e textos em metodologia do Ensino Superior. Campinas: Papirus, 2001.

SOUZA, Nadia Aparecida de. BORUCHOVITCH, Evely. Mapas conceituais: estratégia de ensino/aprendizagem e ferramenta avaliativa. Educação em Revista. Belo Horizonte, v. 26, n. 3, p. 195-218, 2010.

TARDIF. Maurice. Saberes Docentes e formação profissional, 6. ed. Petrópolis, RJ: Vozes, 2006.

UNIVERSIDADE ESTADUAL. Programa da disciplina de avaliação. 2014.

VASCONCELLOS, Celso. S. Avaliação: concepção dialética-libertadora do processo de avaliação escolar. São Paulo: Libertad, 2000.

VILLAS BOAS, B. M. de F. Portfólio, avaliação e trabalho pedagógico. Campinas: Papirus, 2003.

ZEICHNER, Kenneth M. Formando professores reflexivos par a educação centrada no aluno: possibilidades e contradições. In: BARBOSA, Raquel Lazzari Leite (Org.). Formação de educadores: desafios e perspectivas. São Paulo: Editora UNESP, 2003, p. 35-55. 


\section{Dados das Autoras}

\section{Dados das Autoras}

\section{Mari Clair Moro Nascimento}

Doutoranda em Educação pela Universidade Estadual Júlio de Mesquita Filho. Professora na Universidade Norte do Paraná na Educação a Distância. Marília/SP - Brasil. mariclairmoro@hotmail.com.

\section{Raquel Lazzari Leite Barbosa}

Doutora em Educação pela Universidade Estadual de Campinas. Professora Orientadora do Programa de Pós-Graduação em Educação da Faculdade de Filosofia e Ciências na Universidade Estadual Júlio de Mesquita Filho. Marília/SP - Brasil. raqueleite@uol.com.br.

\section{Anelise Martinelli Borges de Oliveira}

Doutora em Educação pela Universidade Estadual Júlio de Mesquita Filho. Integrante do Grupo de Estudos e Pesquisas sobre Linguagem, Ensino e Narrativa de Professores - GEPLENP - certificado pelo CNPq. Marília/SP - Brasil. anelisemartinelli@hotmail.com.

Submetido em: 18-12-2015

Aceito em:2-3-2017 